\title{
Mentoring first year study groups - benefits from the mentors' perspective
}

\author{
Nadia Rahbek Dyrberg ${ }^{1}$ and Claus Michelsen ${ }^{1}$ \\ ${ }^{1}$ Laboratory for Coherent Education and Learning, Faculty of Science, University of Southern Denmark, Odense, Denmark \\ For correspondence: nrdk@sdu.dk
}

\begin{abstract}
The 'study group concept' at the University of Southern Denmark (SDU) was implemented to aid first year students' transitional challenges. A mentor (an older student) is affiliated each study group to facilitate productive group work, bring awareness to study habits, and share his/her own experiences with life as a student. The study explores the mentors' benefits of their employment $(n=43)$ and compares the mentors to non-employed students. Data was obtained through a questionnaire composed of open and closed questions. Findings suggest that a large portion of the mentors have expanded their network (67\%), increased their consciousness of study habits $(60 \%)$, and developed academic abilities $(40 \%)$. The mentors constitute a group of students highly engaged in the university community compared to the non-employed students. Awareness of the benefits of student employment is important to both decision makers and students themselves.
\end{abstract}

Keywords: Mentors, study groups, student employment, first year

\section{Introduction}

Transitioning from upper secondary school to tertiary education provides challenges to many students (e.g. Brinkworth et al., 2009; Holmegaard et al., 2014). To aid this transition, colleges and universities worldwide offer induction programmes to new first year students (Tinto, 2006). The induction programmes vary in length and intensity; some programmes take place prior to semester start as 'Freshers week' whereas others run simultaneously with the students' first courses (Laing et al., 2005). The persons involved in organising and conducting these induction programmes are often support staff (e.g. coordinators of student affair initiatives) and older students. These older (more experienced) students often acts as peer mentors for (less experienced) first year students in their transition from upper secondary school to university or college (e.g. Chester et al., 2013; Fox et al., 2010; Hall and Jaugietis, 2011). A similar concept called the 'study group concept' is subject for this paper. It has been implemented at a Danish university with great success in terms of student satisfaction and learning outcomes with regards to both the academic content as well as learning to be a university student (Dyrberg et al., 2015). In the study group concept, experienced students are employed by the science faculty to mentor first year students' study groups. These study groups are predefined (the study groups are assigned members prior to semester start) and exits across courses, constituting a firm base and a small working community for the first year students. Each study group is mentored by an experienced and trained student - a 'study group mentor' - who facilitates group work and acts as a role model in the process of becoming an accomplished and independent university student. Thus, the study group concept tackles six issues called for by Fox et al. (2010) in their concluding advise on how to implement peer mentoring programmes: I) identify mentees (first year students are recommended), II) select mentors (experiences student who are able to share experiences are recommended) III) identify intervention goals, IV) plan mentor training, V) assign a 
person to handle operational issues (e.g. allocating rooms to meet in), and VI) conduct running evaluation with focus on possible development.

The present paper is centred on the study group mentors and asks if they too benefit from their role of mentoring first year students. Studies reporting on new initiatives where experienced students either teach or in various ways mentor less experienced students often focus on the benefits for the less experienced students (e.g. Altus, 2015; Bordes and Arredondo, 2005). One of the few researchers to touch upon the benefits of the employed students are Ocel et al. (2003) who found that medical students volunteering as teaching assistants experienced increased skills within communication and regular teaching. Another example is Boyle et al. (2010) who report on an initiative using experienced students as mentors for newly enrolled students in distance education programmes. In addition to a $20 \%$ retention gain among the mentees, the mentors felt that they too had gained from the experience as it allowed them to feel involved and valued. Others have studied teaching assistants' benefits in terms of preparation for a future career in academia (e.g. Austin, 2002). Thus, it seems clear that benefits exits for both the less experienced and the more experienced students involved in various induction or teaching initiatives at higher educational institutions. These are benefits worth considering for university policy makers when deciding on which kind of initiatives to implement at their institution.

The aim of the present study is twofold. First, we wish to share our experiences with the development of the study group concept from the science faculty at University of Southern Denmark (SDU). We provide enough details for the concept to be adapted by others. As the benefits of the study group concept are already established for the first year students (Dyrberg et al., 2015), our second aim is to explore the benefits gained from employment as a study group mentor.

Before turning to the context of the study, literature examples of the benefits associated with being a student employee at a higher education institution are provided.

\section{Benefits from student employment}

Students are employed at colleges and universities all over the world to handle various tasks. The student employees are often essential parts of new initiatives towards younger students, for example, to ease the transition into higher education and/or to improve the teaching or learning experience and effectiveness (e.g. Chester et al., 2013; Colvin and Ashman, 2010; Fox et al., 2011).The distinction between the different student employment types (typically mentors, tutors and teaching assistants) is however blurry, as different educational institutions use different terms for roles which are overlapping in function, responsibilities, and conditions of employment. Within the mentor-category alone multiple definitions exist, and mentoring programmes vary greatly in e.g. objectives, duration, management, and mentor/mentee-ratio (Gershenfeld, 2014; Hall and Jaugietis, 2011; Jacobi, 1991). There is extensive literature on benefits for less experienced students, typically first year students, of mentoring programs with older students as mentors, (e.g., Altus, 2015; Bordes and Arredondo, 2005; Skaniakos et al., 2014). An example of alternative use of student mentors is provided by Chuang et al. (2003). They describe how technology undergraduate and graduate students are employed to help faculty at US teacher education programmes integrate educational technology in their teaching.

The role of tutors is often described as a kind of teaching assistant. In New Zealand Retna et al. (2009) describe tutors who are involved in large class courses. They assist teaching, assess the younger students' work, and provide feedback. In Denmark, the term tutor is typically used for a student volunteering to support the social integration of first year. Thus, the Danish tutors are not involved in teaching. Instead their role corresponds to the second mentor type identified by Skaniakos et al. 
(2014) in a study of the use of mentors in Finnish educational institutions; socialising and informing mentors arranging social events and introductory tours.

With regards to teaching assistants, some researchers have studied the TA position as faculty preparation (e.g., Austin, 2002; Smith and Kalivoda, 1998). But only few have, evaluated positive feedback effects that exist while the student employee is still a student. As mentioned earlier, Ocel et al. (2003) found that medical students benefitted from an experience volunteering as TAs during their third year of studies. They experienced increased skills in communication, giving lectures, and oneon-one teaching, and they also regularly used the academic knowledge they had gained. Similar findings are reported in other teaching situations (Schalk et al., 2009; McKeegen, 1998) as wells as in a mentor situation (Hall and Jaugietis, 2011).

Colvin and Ashman (2010) evaluated a mentor programme by (among other things) assessing benefits and risk for the three involved groups; students, mentors and instructors. The main benefits associated with being a mentor were being able to support students, reapplying concepts in one's own life, and developing relations, and the main risk was the vulnerability arising from exposing one's experiences and reflections. Furthermore, an interesting point was that "students, mentors, and instructors all have different perspectives about a mentor's role and how that role should be enacted" (Colvin and Ashman, 2010, p. 121). Therefore it is important to make clear what role the mentor is supposed fill and what is not in the job description. This is in line with our own experiences continuously working to further develop the study group concept.

Dyrberg (2016) found increased levels of university belonging among study group mentors and other student employees e.g. teaching assistants and social tutors compared to students who were not employed at their university. University belonging is a complex psychological concept derived from sense of belonging. It encompasses feeling acknowledged for one's capabilities, having positive relations with staff as well as other students, and feeling as a part of the community (Pittman and Richmond, 2008). In addition to these positive emotions, university belonging is associated with greater students success through academic motivation and intention to persist (e.g. Beyers and Goossens, 2002; Strayhorn, 2012). Although causal relationships remains to be firmly established, there are indications that students develop a higher sense of belonging after involving themselves more in the campus community (Strayhorn, 2012). Dyrberg (2016) claims that this also apply to the formal involvement of student employment. She further hypothesises that a positive feedback loop exists: so that involvement (both through volunteer work in students organisations and through formal employment at the university) affects positively on sense of belonging and sense of belonging also positively affects the students' inclination to engage and involve themselves in the university community.

From the above mentioned examples it seems clear, that there are benefits associated with being a student employee at one's university. These are benefits that show themselves while the student is still a student as well as after graduation. With the study group mentors at SDU as case study, we explore how the student employees themselves experience and articulate such benefits. In order to understand the context these study group mentors are employed in, we provide a description of the study group concept below.

\section{The study group concept}

The study group concept is implemented at SDU alongside the Three Phase Model (Michelsen and Dyrberg, 2014) which is the general model for teaching and learning at the science faculty. The study group concept applies specifically to the first year of studies. A thorough description of the concept is 
provided in Dyrberg et al. (2015). But as the paper is in Danish, we provide a summary of the concept and the attained experiences here.

The study group concept was developed as part of a larger project 'Education, we are proud of' at the Faculty of Science, SDU, which began in 2011. The aim was to support first year students' transition from upper secondary students to independent university students. The students should feel that hard work is required to complete a university programme. But at the same time they should feel that they are not alone in this transformation. On that basis, study groups were established to provide students with a safe base to develop academic competencies and share experiences. An older student was affiliated each study group to mentor their academic work and act as a role model discussing everything from productive study techniques to challenges associated with being a first year student. A large portion of students at SDU are first generation in academia and know little about the university upon arrival. Therefore, part of the study group mentors' task is also to introduce the structure of the university and the implicit expectations held by the institution and by the teachers. From Tinto's prominent model of student departure (1987), it follows that successful transitions (leading the students to stay in their study programme) requires the students to be both academically and socially integrated. Brennan et al. (2010) also signify the importance of the study programmes' social context and use the concept 'social mediating'. The study groups are meant to provide the students with a physical space and with opportunities to aid these integration processes. Another inspiration for the development of the study group concept was 'communities of practices' (Wenger, 1998). In the study groups, the students should be able to actively engage in the scientific content and establish a learning community that prepares them to participate in the community of scientific practice and become full members.

In 2011, predefined study groups without affiliated mentors were attempted. Here students themselves were supposed to plan and organise the group meetings. But without assignments from teachers and without some form of authority encouraging the group work, the establishment of viable study groups failed - the study groups fell apart. Hereafter, in 2012 the study group mentors were employed to facilitate productive group work. Rybczynski and Schussler (2011) also found evidence to support that some form of guidance is needed in order to establish successful study groups. Furthermore, they concluded that the potential outcome of study group will be enhanced when making the students aware of potential group dynamic challenges, and when teachers assign tasks to focus the study groups' work. The study group concept at SDU responds to both of these recommendations: study group mentors facilitate the group work and makes students aware of group dynamics, and teachers develop assignments for the students to work with.

\section{Practical implementation}

All first year students at the Faculty of Science, SDU, are assigned to a class of approximately 26 students. This class is further divided into three study groups of 8-9 students and one study group mentor is assigned to each study group. The three study group mentors affiliated one class constitute a team that discuss the planning and handling of the groups and cover for each other when needed. The study groups are predefined upon semester start but halfway through first semester a new formation of groups takes place. This time the students themselves divide the class into study groups within a set of guidelines and under supervision by the mentors. The aim of making new these groups is threefold: I) to provide students with opportunity to break loose from a role they had undertaken (more or less willingly) in the first study group, II) to induce ownership of the study group, and III) to give the students opportunity to cooperate with a variety of students with different personality types and with different perspectives and preferences towards working methods.

The study groups produce and sign a contract describing e.g. ambition level and work ethics in the group. The content of contract is entirely up to the group members but each member has to agree and 
sign the document, thereby making it an instrument to handle or even prevent possible conflicts. The study groups meet two-three times each week and the study group mentors are present about half of the group sessions. Each session (90 mins.) is allocated to a specific course and the teachers of this course have designed assignments especially for this purpose. The assignments incorporate cooperative learning elements and encourage discussion of the subject matter. The intensity of the study group mentors' presence is lowered throughout the first semester, and in the second semester the first year students only meet with their study group mentor once. Hereafter, the study groups work independently.

\section{The study group mentors}

As described earlier, the study group supervisors are experienced students employed by the faculty. They are on their third year of studies (final year of bachelor programme) or above (master students), and are selected through a process of applications and job interviews. When selecting students for employment, the coordinators choose students who reflect on being a university student and on the benefits and challenges of doing group work. The academic performance is typically medium to high but this is not a prime concern for employment. If the first year students should identify themselves with their study group mentor (and see him/her as a role model), it is important that the mentor is able to relate to the students, understand their frustrations/insecurities, and willing to share his/her own experiences - both good and bad experiences.

The study group mentors complete a three-day training programme preparing them for their role as mentor, facilitator, and role model. The content of these days is widespread ranging from cooperative learning strategies, different learning styles, communication, and conflict mediation to the responsibility of being a representative for the faculty. The scope of the task of being a study group mentor is also an important subject during the training programme. It is stressed that the study group mentors are not instructors; they are not supposed to teach or know the answers to the assignments provided by the teachers. Whether or not the individual study group mentor wants contact to the first year students through Facebook, cell phone, and/or email is something the study group supervisors are asked to consider before meeting their group for the first time. The training programme ends with a reception where a prominent person e.g. vice dean of studies hands over diplomas. By doing so, the coordinators wish to signal that the role of the study group mentors is important and appreciated by the faculty.

The coordinators of the study group concept are daily contact persons for the study group mentors. The coordinators are available to clarify questions and to listen if the mentors want sparring on a challenge with the study group or just want to share a successful experience. This also provides the coordinators with unique insights in what goes on with the first year students. The mentors also provide feedback on specific assignments and on how the students generally feel about the courses to the first year teachers.

\section{First year students' experiences}

When asked to mention one positive and one negative aspect about the study group concept, the students' responses reveal a great variety of experiences. Of good aspects, the first year students mention academic, motivational, and social advantages. The academic advantages centre around: I) development of competences in cooperation (especially in relation to their future in the job marked), II) academic advantages in being able to supplement and help each other and apply multiple perspectives, III) increased understanding of the subject matter, and IV) possibility to ask questions and discuss the content. The motivational aspects lie primarily in a motivation to get the (home) work done and to show up to class and group meetings (because of the other group members' expectations to you). The social elements often consist of establishing (close) contacts to fellow students. The negative aspects mentioned by the first year students typically concern the large size of the groups, 
lack of relevant assignments, and varying commitment, seriousness, and levels of ambition among group members.

Generally, the first year students were very happy with their study group mentor, who became a person they looked up to. The students appreciated that their mentor was able to provide insight into the student life but the students also expressed that the importance of the mentor fades out during first semester.

\section{Methods}

Data on the study mentors experiences were collected through a questionnaire distributed at the end of the spring semester 2014. The questionnaire was managed with SurveyXact and was distributed to third, fourth, or fifth year science students. These students were enrolled in a science programme at SDU in 2009, 2010 or 2011 and were either master students or third year undergraduate students. These year groups were chosen because three years of studies is the minimum requirement for employment as a study group supervisor. As the questionnaire was distributed in the exam period some students might have been mentally preoccupied or too busy to answer the questionnaire. In total, 161 respondents responded to the questionnaire (response rate of $46 \%$ ) - of these 43 students were or had been employed as study group mentors, and 85 students were not and had never been employed at the science faculty. These 128 students were included in this study. Students who were or had been employed in other positions than study group mentor were excluded from the study.

The questionnaire consisted of demographic questions, open and closed questions/items regarding student employment, and a test for university belonging. Findings regarding university belonging are reported elsewhere (Dyrberg, 2016), and findings regarding other types of employment than the position as study group mentor will be subject of a future study.

The idea that being employed as a study group mentor positively affected the employed students' identity as students arose from the coordinators' daily communication with the mentors. The study group mentors continuously articulated elements that lead the coordinators to hypothesise that besides an increased sense of belonging to the science faculty, the study group mentors also developed I) an expanded network, II) an increased consciousness of their own study habits, and III) increased academic abilities. Thus, the questionnaire was designed to evaluate these three elements of possible personal development.

The 43 mentors included in the study were distributed across the various study programmes offered by the science faculty in a manner resembling the distribution among all study group mentors. Therefore it is considered representative. The questionnaire responses were analysed (and reported) with descriptive statistics of the closed questions/items and conventional content analysis (Hsieh and Shannon, 2005) of open responses. The quantitative data provides an overview of the study group mentors compared to the non-employed students as well as the study group mentors' experiences and perceived benefits of their position. The open responses exemplify and nuance these experiences to aid the interpretation of the findings.

\section{Findings}

A large portion of the study group mentors (61\%) were also or had been employed at other student positions at the faculty e.g. as teaching assistants or social tutors. Furthermore, $37 \%$ of the study group mentors were engaged in volunteer work operating at the university. This amount of volunteer work among the study group mentors is remarkable when comparing to the group of non-employed student: only $5 \%$ of the non-employed student were engaged in volunteer work at the university (figure 1). 


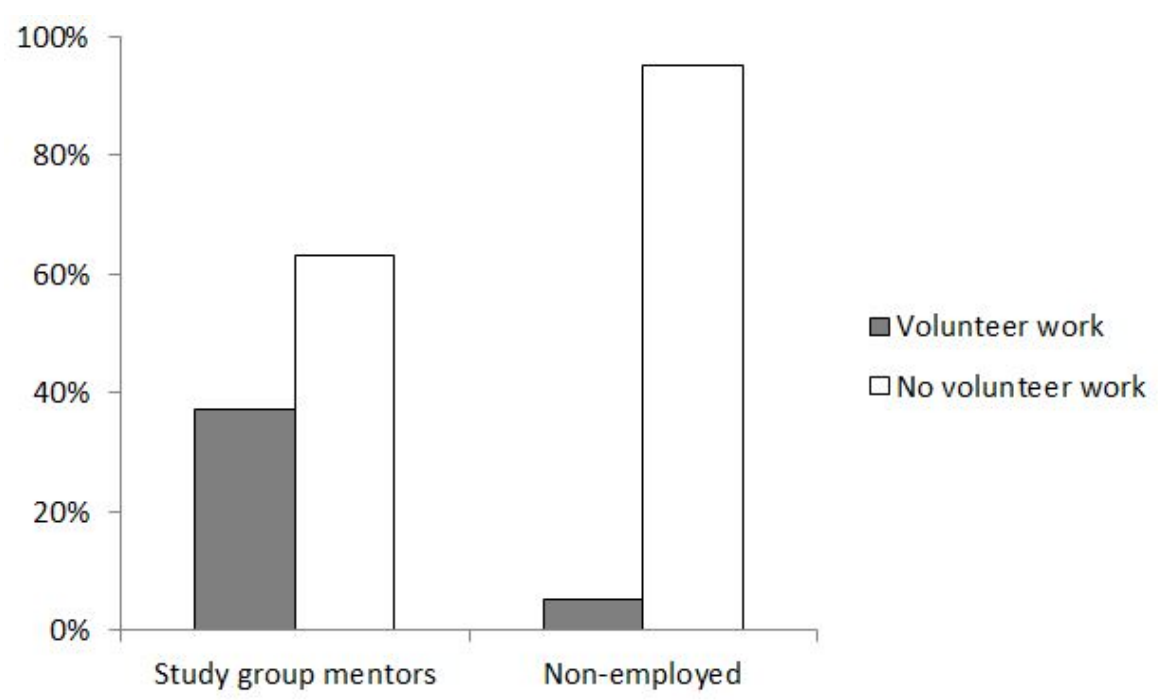

Figure 1. Percentage of study group mentors $(n=43)$ and non-employed $(n=83)$ students engaging in volunteer work at the university.

Differences between the study group mentors and the non-employed students are also revealed in how much time they spent at campus each week and when describing their social circle. The study group mentors spend more time (approx. 9.1 hours/week) at campus outside of scheduled classes and necessary time in laboratory in connection with projects, than the non-employed students (approx. 6.4 hours/week). Figure 2 visualises how the study group mentors and the non-employed students describe their social circle. For $88 \%$ of the study group mentors compared to $60 \%$ of the nonemployed students, the social circle primarily is composed of other persons who are either students or employees at the science faculty. On the other hand, the portion of respondents describing a high degree of their social circle to be composed of persons outside the university (SDU) is larger among the non-employed $(29 \%)$ than the study group mentors $(10 \%)$.

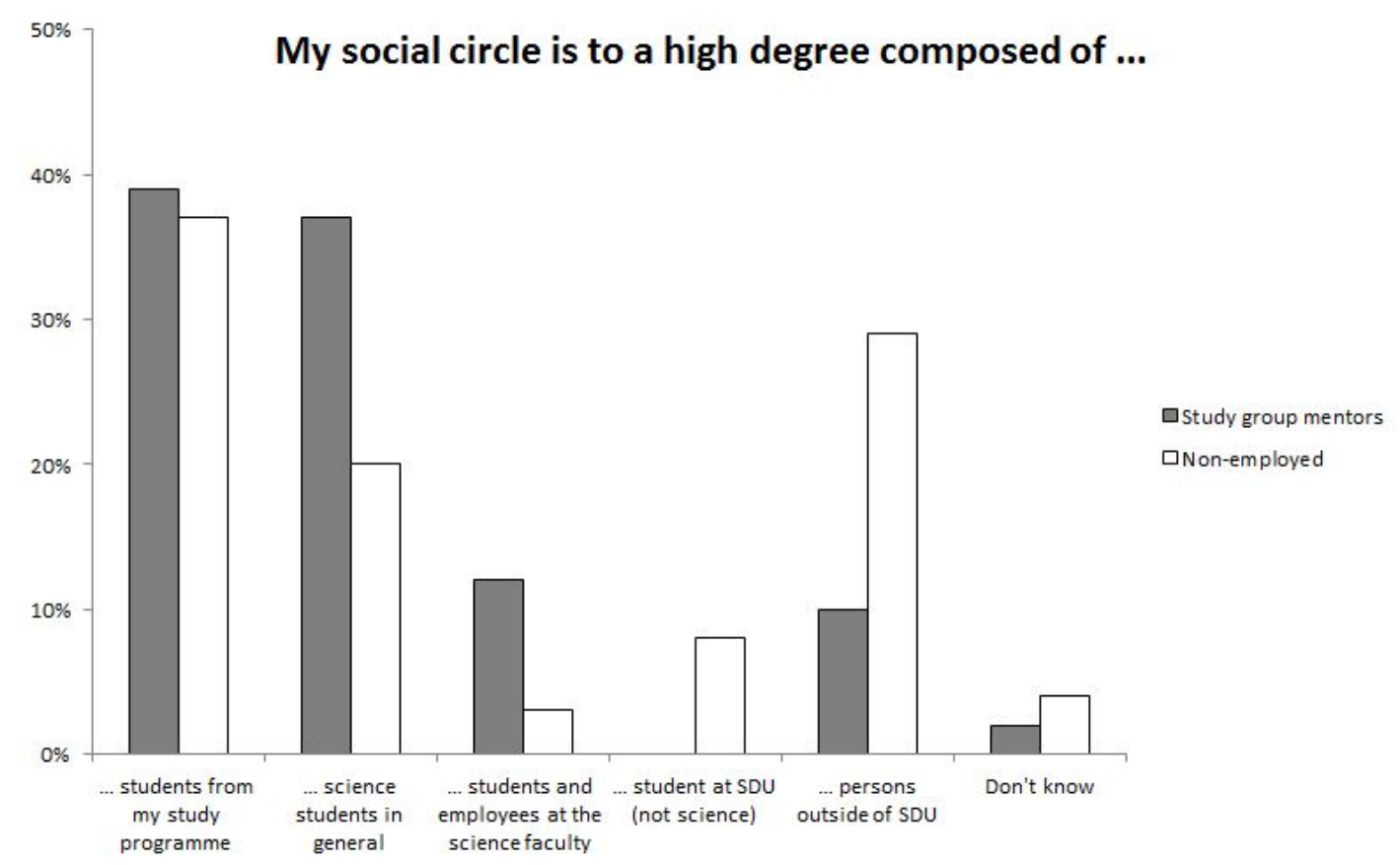

Figure 2. Study group mentors' $(\mathrm{n}=41)$ and non-employed students' $(\mathrm{n}=79)$ answers to a question about the composition of their social circle. Respondents were asked to choose the answer best describing them. 


\section{Mentors' experiences}

In order to tap into the mind-set of the mentors, the study group mentors were asked to write the first thing coming to mind when asked "In your position as a study group mentor, who do you work for?" In total, 39 provided an answer to this open question. Of these 15 wrote that they work for the first year students, and 26 wrote that they work for the science faculty, the university, or the study group coordinators (two mentioned both the students and faculty). One mentor took the open response field as an opportunity to phrase his/her personal objective working as a mentor for first year students: "I work to give the new students the best possible beginning at their studies and to give them the right tools to reach their goals both academically and socially."

Table 1 shows the mean responses to the closed questions about the mentors' experiences. Generally, the study group mentors feel that they perform an important job $(M=5.22)$, that they constitute an important part of the first year induction $(\mathrm{M}=5.67)$, and that they can make a difference for the individual first year students $(\mathrm{M}=5.59)$. The mentors also feel that the coordinators are interested in their experiences as mentors $(\mathrm{M}=5.97)$. But the perceived interest from the teachers at the first year courses is considerably lower $(\mathrm{M}=3.82)$.

Table 1. Mean (M) answer and standard deviation (SD) of mentors' response to statements regarding their position and experiences as study group mentors. (1: completely disagree - 7: completely agree).

The number of respondents varies as respondents choosing "Don't know" were excluded in the calculation of means.

\begin{tabular}{lcc}
\hline Statement & $\mathrm{M}$ & $\mathrm{SD}$ \\
\hline $\begin{array}{l}\text { I feel that the contact persons/coordinators are interested } \\
\text { in my experiences ( } \mathrm{n}=31 \text { ) }\end{array}$ & 5.97 & 1.68 \\
$\begin{array}{l}\text { I feel that the teachers at the first year are interested in my } \\
\text { experiences (n=28) }\end{array}$ & 3.82 & 1.54 \\
$\begin{array}{l}\text { As a study group mentor I perform an important job } \\
\text { (n=32) }\end{array}$ & 5.22 & 1.54 \\
$\begin{array}{l}\text { As a study group mentor I constitute an important part of } \\
\text { the science faculty's induction of first year science } \\
\text { students (n=33) }\end{array}$ & 5.67 & 1.56 \\
$\begin{array}{l}\text { As a study group supervisor I can make a difference for } \\
\text { the individual students (n=32) }\end{array}$ & 5.59 & 1.70 \\
\hline
\end{tabular}

The mentors' responses regarding the three possible benefits in focus for this study are summarised in table 2. Most study group mentors feel that they have extended their network (67\%) and increased their consciousness of their own study habits $(60 \%)$ through the position as study group mentor, and approximately $40 \%$ feel that they have increased their academic abilities. With regards to network, the study group mentors' open responses describe how their new relations are both horizontal (other study group mentors) and vertical (first year students and staff) in the university hierarchy. Regarding the consciousness of study habits, some mentors point out that they had to be conscious about in order to be able to pass it on to the first year students. Others refer to the training days as the point they got to think about their own study habits, and others again suggest that their increased consciousness is related to them getting older and more experienced in their own studies.

The question about academic abilities is more blurry. A portion of the mentors feel they have increased their competences within (academic) communication, teaching, and doing group work. But not all mentors categorise these competences as strictly academic. Others feel that the chance to work with the first year content provided them with useful repetition. 
Table 2. Summary of answers regarding network, consciousness of study habits and academic abilities. Questions were phrased as "Through your position as a study group mentor, do you feel that you have obtained...?"

\begin{tabular}{|c|c|c|c|}
\hline \multirow{2}{*}{$\begin{array}{c}\text { Question } \\
\text { Extended network? }\end{array}$} & \multicolumn{2}{|c|}{ Distribution of answers } & Examples \\
\hline & $\begin{array}{c}\text { Yes: } \\
\text { No/doubt: }\end{array}$ & $\begin{array}{l}67 \% \\
33 \%\end{array}$ & $\begin{array}{l}\text { "Yes. I talked with people I would not have talked } \\
\text { with otherwise as our study programmes do not cross } \\
\text { each other." }\end{array}$ \\
\hline $\begin{array}{l}\text { Increased } \\
\text { consciousness of } \\
\text { own study habits? }\end{array}$ & $\begin{array}{c}\text { Yes: } \\
\text { No/doubt: }\end{array}$ & $\begin{array}{l}60 \% \\
40 \%\end{array}$ & $\begin{array}{l}\text { "Yes. To explain stuff you got to understand it } \\
\text { yourself. During my work as a mentor I was asked } \\
\text { questions about my own study habits. In connection } \\
\text { with one of the meetings I presented some good } \\
\text { advises on study habits. It made me very conscious } \\
\text { about it. The students' reactions were very positive." }\end{array}$ \\
\hline $\begin{array}{l}\text { Increased academic } \\
\text { abilities? }\end{array}$ & $\begin{array}{c}\text { Yes: } \\
\text { No/doubt: }\end{array}$ & $\begin{array}{l}40 \% \\
60 \%\end{array}$ & $\begin{array}{l}\text { "Not strictly academic competences but more } \\
\text { competences related to doing good group work." } \\
\text { "I am more conscious about the way I communicate } \\
\text { academically and how different problems are solved." }\end{array}$ \\
\hline
\end{tabular}

\section{Discussion}

Aiding first year students transitional challenges through peer mentoring programmes are becoming increasingly popular (Gershenfeld, 2014; Jacobi, 1991), and the benefits for the mentees are widely established (e.g. Boyle et al. 2010; Chester et al., 2013; Hall and Jaugietis, 2011). The findings in this paper indicate, that the study group concept with predefined study groups and affiliated study group mentors at SDU does not only benefit the first year students but also the more experienced students employed as mentors. The study group mentors seem to perceive their position as study group mentor as important and they feel that the coordinators are interested in listening to their experiences. The deliberate appreciatory strategy exerted by the coordinators seems to work. However, it seems that the interest from the first year teachers is not quite as evident to the study group mentors. This indicates a point of possible improvement of the concept. The study group mentors possess intensive knowledge of the first year students' well-being and struggles as well as in-depth insight into the first year students' perceptions of the courses and the teaching. Thus, the mentors constitute a valuable feedback opportunity for the first year teachers. In the study of a similar mentor programme, Colvin and Ashman (2010) found a similar claim in the comments from instructors (faculty staff) who had a mentor in their class. Most instructors identified the opportunity "to receive feedback about the class that they might not normally receive from students" as the main benefit.

The mentors who indicated having increased their network through their employment and identify vertical relations (younger and older student as well as employees at the science faculty) are interesting. Developing these new relations combined with proudness to perform an important task and being acknowledged for this might be part of the explanation of why study group supervisors have been proven to have a high sense of university belonging (Dyrberg, 2016).

The findings presented in this study show that the students being selected for employment as study group mentors constitutes a group of students that are highly engaged in the study environment compared to non-employed students. This increased engagement is indicated by more time spent on campus and greater involvement in volunteer work at the university. Whether or not, the more engaged students apply for the job as study group mentor to a higher degree than less engaged students, or the mentor position induces engagement cannot be determined from this study. But different patterns of engagement clearly exist. We have not included other types of student employments in this study but we suspect that these students too are more engaged in campus 
activities than the non-employed student. Within the group of study group mentors the majority (61 $\%)$ were also or had been employed in other positions at the science faculty.

The task of propagating productive study techniques to the first year students seems to induce reflections of the study group mentor's own study habits. We speculate that this reflective process might induce better study techniques for the study group mentors as well as for the first year students. In line with the recommendation from Colvin and Ashman (2010), it was made clear to both the mentors and the first year teachers from the beginning that the mentors are not teaching assistants. The mentors are not expected to know the answers to all academic assignments presented to the study groups. The mentors who in spite of this believe to have developed their academic abilities often mention increased competences in explaining and communicating, and the repetition of first year curriculum was considered an appreciated opportunity. These findings are consistent with Ocel et al. (2003) and Schalk et al. (2009) who among others thing reported increased communicative skills. Schalk et al. (2009) compared the experience of undergraduate teaching assistants to that of undergraduate research assistants and concluded that the teaching experience was a valuable alternative to the research experience. The teaching experience "is an effective option for developing skills and knowledge in undergraduates that are essential for careers in science" (Schalk et al., 2009, p. 32). We propose that the same applies for the mentor experience.

The present study was a small scale study with regards to both number of participants and length of questionnaire. But still it provided clear indications that the benefits of a concept such as the study group concept not only benefits the first year students but the employed (older) students as well. Further studies are needed to determine transferability of findings to other contexts and other types of student employees. A few studies have already come to similar conclusions but the vast variations in the management of mentor programmes complicate or even hinder potential comparisons. Therefore future studies could benefit from having a set of background variables that is always informed e.g. How are the mentors chosen? Are they paid? Do they receive training? When investigating possible benefits of employment, such information about the context the students are employed in is necessary.

The present study focussed on benefits that exist while the mentors are still students themselves. However, we speculate that some benefits transcend the student life and will unfold during the mentors' further career in the job marked - possibly even enhancing their employability. This is another interesting aspect to be explored in future studies.

\section{Concluding remarks}

In general, the mentors express varying outcomes from their position as study group mentors. But still, we put forward the hypothesis that being employed as a study group mentor or in a similar position triggers a process that benefits the employed students while they are finishing their own studies. This is a positive side-effect of the study group concept that was not taken into account in the initial arguments and reasoning for implementing the concept. Knowing that implementing an initiative such as the study group concept has positive effects that supersedes the first year of studies is a strong argument for implementation at other institutions as well. In this paper we have provided enough practical details for the concept to be adapted by others. Awareness of the benefits of being employed as a student is also important to students seeking opportunity to develop their competences. Informing students of these possibilities may also render the positions more attractive.

\section{Acknowledgements}

We extend our gratitude to the study group mentors for participating in the questionnaire and for their outstanding work with the first year students. Furthermore, we thank all the people who helped 
developing and implementing the study group concept and the Faculty of Science, University of Southern Denmark, for willingness to implement the concept.

\section{References}

Altus, J., (2015). Answering the call: How group mentoring makes a difference. Mentoring \& Tutoring: Partnership in Learning, 23(2), 100-115.

Austin, A. E., (2002). Preparing the next generation of faculty: Graduate school as socialization to the academic career. The Journal of Higher Education, 73(1), 94-122.

Beyers, W. and Goossens, L., (2002). Concurrent and predictive validity of the student adaption to college questionnaire in a sample of European freshmen students. Educational and Psychological Measurement, 62(3), 527-538.

Bordes, V. and Arredondo, P., (2005). Mentoring and 1st-year latina/o college students. Journal of Hispanic Higher Education, 4(2), 114-133.

Boyle, F., Kwon, J., Ross, C., and Simpson, O., (2010). Student-student mentoring for retention and engagement in distance education. Open Learning, 25(2), 115-130.

Brennan, J., Edmunds, R., Houston, M., Jary, D., Lebeau, Y., Osborne, M., et al., (2010). Improving what is learned at university: An exploration of the social and organisational diversity of university education. Oxfordshire, England: Routledge.

Brinkworth, R., McCann, B., Matthews, C., and Nordström, K., (2009). First year expectations and experiences: Student and teacher perspectives. Higher Education, 58(2), 157-173.

Chester, A., Burton, L. J., Xenos, S., and Elgar, K., (2013). Peer mentoring: Supporting successful transition for first year undergraduate psychology students. Australian Journal of Psychology, 65(1), 30-37.

Chuang, H., Thompson, A., and Schmidt, D., (2003). Faculty technology mentoring programs. Journal of Computing in Teacher Education, 19(4), 101-106.

Colvin, J. W. and Ashman, M., (2010). Roles, risk, and benefits of peer mentoring relationships in higher education. Mentoring \& Tutoring: Partnership in Learning, 18(2), 121-134.

Dyrberg, N. R., Kromann, C. G., and Michelsen, C., (2015). Studiegrupper og studiegruppevejledere på naturvidenskabelige universitetsuddannelser [Study groups and study group mentors at tertiary science programmes]. MONA - Matematikog Naturfagsdidaktik, 4, 44-64.

Dyrberg, N. R., (2016). University Belonging: The relation between students' sense of belonging and being a student employee at the university. Manuscript submitted for publication.

Fox, A., Stevenson, L., Connelly, P., Duff, A., and Dunlop, A., (2010). Peer-mentoring undergraduate accounting students: The influence on approaches to learning and academic performance. Active Learning in Higher Education, 11(2), 145-156.

Gershenfeld, S., (2014). A review of undergraduate mentoring programs. Review of Educational Research, 84(3), 365-391.

Hall, R., and Jaugietis, Z., (2011). Developing peer mentoring through evaluation. Innovative Higher Education, 36(1), 41-52.

Holmegaard, H. T., Madsen, L. M., and Ulriksen, L., (2014). A journey of negotiation and belonging: Understanding students' transition to science and engineering in higher education. Cultural Studies of Science Education, 9(3), 755-786.

Hsieh, H.-F. and Shannon, S. E., (2005). Three approaches to qualitative content analysis. Qualitative Health Research, 15(9), 1277-1288.

Jacobi, M., (1991). Mentoring and undergraduate academic success: A literature review. Review of Educational Research, 61(4), 505-532.

Laing, C., Robinson, A., and Johnston, V., (2005). Managing the transition into higher education. Active Learning in Higher Education, 6(3), 243-255.

McKeegan, P., (1998). Using undergraduate teaching assistant in a research methodology course. Teaching in Psychology, 25(1), 11-14.

Michelsen, C. and Dyrberg, N. R., (2014). Trefasemodellen: Didaktisk planlægning af lokalprogression [The Three Phase Model: Didactical planning of local progression]. Dansk Universitetspædagogisk Tidsskrift, 9(16), 18-30.

Ocel, J. J., Palmer, B. A., Wittich, C. M., Carmichael, S. W., and Pawlina, W., (2003). Outcomes of the gross and developmental anatomy teaching assistant experience. Clinical Anatomy, 16(6), 526-530.

Pittman L. D., and Richmond, A., (2008). University belonging, friendship quality, and psychological adjustment during the transition to college. The Journal of Experimental Education, 76(4), 343-362.

Retna, K. S., Chong, E., and Cavana, R. Y., (2009). Tutors and tutorials: Students' perception in a New Zealand university. Journal of Higher Education Policy and Management, 31(3), 251-260.

Rybczynski, S. M., and Schussler, E. E., (2011). Student use of out-of-class study groups in an introductory undergraduate biology course. Life Science Education, 10(1), 74-82.

Schalk, K. A., McGinnis, J. R., Harring, J. R., Hendrickson, A., and Smith, A. C., (2009). The undergraduate teaching experience offers opportunities similar to the undergraduate research experience. Journal of Microbiology $\mathcal{E}$ Biology Education, 10(1), 32-42.

Skaniakos, T., Penttinen, L., and Lairia, M., (2014). Peer group mentoring programmes in Finnish higher education: Mentors' perspectives. Mentoring \& Tutoring: Partnership in Learning, 22(1), 74-86.

Smith, K. S. and Kalivoda, P. L., (1998). Academic morphing: Teaching assistant to faculty member. In M. Kaplan (Ed.), To Improve the Academy. (pp. 85-102). Vol. 17. Stillwater, OK: New Fonuns Press.

Strayhorn, T. L., (2012). College students' sense of belonging: A key to educational success for all students. New York: Routledge.

Tinto, V., (1987). Leaving college: Rethinking the causes and cures of student attrition. Chicago: The University of Chicago Press. 
Tinto, V., (2006). Research and practice of student retention: What next? Journal of College Student Retention: Research, Theory $\mathcal{E}$ Practice, 8(1), 1-19.

Wenger, E. (1998). Communities of Practice: Learning, meaning and identity. Cambridge, England: Cambridge University Press. 